\title{
NUTRIÇÃO MINERAL DE HORTALIÇAS XVIII. Efeito da omissão dos macronutrientes e do boro, no desenvolvimento e na composição química da ervilha *
}

\author{
M. A. C. Santos ** \\ H. P. HaAg \\ J. R. SARruge ***
}

\section{RESUMO}

$O$ presente trabalho teve o objetivo de estudar alguns aspectos da nutrição da ervilha (Pisum sativum, L.), variedade Okaw ("Torta-de-Flor-Roxa") e Asgrow 40 no que concerne:

1 - Efeitos das omissões dos macronutrientes e do boro, na obtenção de um quadro sintomatológico das carências, na variedade Asgrow 40.

2 - Efeitos das carências dos macronutrientes e do boro na produção de matéria seca e composição química na variedade Asgrow 40.

Sementes de ervilha (Pisum sativum, L.) da variedade Asgrow 40, foram postas a germinar em sílica, mantendo-se um teor de umidade adequado. Passou-se a regar as plântulas com soluções nutritivas com omissões dos nutrientes, entre 20 e 25 dias ap6s a germinação. Tão logo se delineou o quadro sintomatológico das carências, as plantas foram coletadas, mensuradas em altura $(\mathrm{cm})$ e peso da matéria seca $(\mathrm{g})$. Divididas em raízes, caules, folhas inferiores e superiores, flores, vagens e analisadas.

Os dados mostram que:

1 - As omissões dos macronutrientes com excessão do magnésio e do enxofre, apresentaram sintomas visuais de deficiência características.

2 - A produção da matéria sèca foi afetada em todos os tratamen. tos com omissão de nutrientes, com excessão daqueles nos quais foram omitidos o magnésio e/ou enxofre.

3 - Os teores dos nutrientes expressos em porcentagem e/ou partes por milhão em folhas apresentando ou não sintomas de carências foram:

* Parte da Dissertação apresentada pelo primeiro autor para obtenção do título de MESTRE pela Universidade de São Paulo. Entregue para publicaçaão em 6/11/72.

** Estação Experimental de Jatinã (IPA) Belem de São Francisco. PE. Bolsista do CNPq - Rio de Janeiro.

**:: Departamento de Química, E.S.A. "Luiz de Queiroz" - U.S.P. 


\begin{tabular}{l|c|c|c|c}
\hline \multirow{2}{*}{ Nutriente } & \multicolumn{2}{c}{ Folhas Inferiores } & \multicolumn{2}{c}{ Folhas Superiores } \\
\cline { 2 - 3 } & $\mathrm{c} /$ sintomas & $\mathrm{s} /$ sintomas & $\mathrm{c} /$ sintomas & $\mathrm{s} /$ sintomas \\
\hline Nitrogênio & $2,4 \%(1)$ & $3,6 \%(1)$ & $0,1 \%$ & - \\
Fósforo & $0,1 \%$ & $0,3 \%$ & - & $0,5 \%$ \\
Potássio & $0,3 \%$ & $2,6 \%$ & $0,2 \%$ & $2,0 \%$ \\
Cálcio & $0,7 \%$ & $2,2 \%$ & $1,0 \%$ & $1,0 \%$ \\
Magnésio & $0,3 \%$ & $0,5 \%$ & $0,3 \%$ & $0,5 \%$ \\
Enxofre & $27 \mathrm{ppm}$ & $0,6 \%$ & $0,1 \%$ & $\mathrm{~J}, 6 \%$ \\
Boro & $0,3 \%$ & $175 \mathrm{ppm}$ & $17 \mathrm{ppm}$ & $78 \mathrm{ppm}$ \\
\hline
\end{tabular}

(1) Folhas inferiores + folhas superiores.

\section{INTRODUÇÃO}

A ervilha (Pisum sativum, L.) pertence a família Leguminosae, subfamília Papilionoidae. Erva cultivada em todo mundo em um grande número de variedades, todas com alto valor nutritivo (HOWARD et alii., 1962).

Originária provavelmente da Etiópia, da Europa Meditarrânea e do Sudoeste da Ásia, no entanto mesmo nestas regiões nunca foi encontrada em estado nativo (ROCHA, 1960).

As variedades são agrupadas em: ervilha para debulhar e ervilha de vagens comestíveis. Em ambos os grupos são encontradas variedades de pequeno porte $(25$ a $50 \mathrm{~cm})$, de porte médio $(50 \mathrm{a} 100 \mathrm{~cm}) \mathrm{e}$ de porte elevado (mais de $100 \mathrm{~cm}$ ). Dentre as do grupo de vagens comestíveis, destaca-se a Torta-de-flor-Roxa (Okaw), de porte elevado, muito rústica, que no Estado de São Paulo tem apresentado os melhores resultados, segundo BERNARDI (1961). Possue maturação escalonada e o seu cultivo se restringe a pequenas áreas. $\mathrm{O}$ seu mercado é como vagens verdes e grãos secos.

Nas variedades para debulhar, é onde se apoiam as indústrias de enlatados, a variedade Asgrow 40 de porte médio, é uma das que tem se destacado pela produtividade e uniformidade de maturação .

O Rio Grande do Sul é o maior produtor de ervilha do Brasil. A cultura ocupa uma área de cerca de 4.800 ha, em duas regiões de produções distintas: Sudeste e Sudoeste do Estado. A produção do ano agrícola de 1966 foi de cerca de $4.000 .000 \mathrm{~kg}$ de grãos verdes (OLIVEIRA et alii., 1968). 
Trata-se de uma cultura que tende a se expandir tanto no Estado do Rio Grande do Sul, como também em outros Estados de clima favorável. Entretanto, são excassos em nosso meio os experimentos com esta leguminosa no que se refere a sua nutrição, base necessária para os programas de adubações.

Os objetivos do presente trabalho são:

1 - Obter um quadro sintomatológico das deficiências de nitrogênio, fósforo, potássio, cálcio, magnésio, enxofre e boro.

2 - Verificar os efeitos das omissões dos citados nutrientes no crescimento e sobre os teores químicos nos diversos órgãos da planta.

\section{MATERIAL E MÉTODOS}

Em vasos de barro pintados internamente com Neutrol 45 * contendo aproximadamente $7 \mathrm{~kg}$ de sílica lavada, foram semeadas cerca de 6 sementes por vaso, mantendo-se um teor de umidade adequado mediante adições periódicas de água. A variedade utilizada foi Asgrow 40.

A germinação deu-se 6 dias após, e passou-se a regar as plântulas por percolação com solução nutritiva conforme Tabela 1 diluida 1:2 nos primeiros 5 dias. Após êste usou-se solução nutritiva completa 1:1 e aos 10 dias com solução nutritiva completa sem diluição. As regas eram feitas tantas quantas necessárias ao dia. As soluções deficientes foram administradas de acordo com esquema a seguir, na página seguinte.

As soluções nutritivas eram trocadas a cada 5 dias, sendo que neste período completou-se o volume dos frascos coletores (1 litro) com água destilada para os tratamentos deficientes nos macronutrientes e com água desmineralizada para o tratamento com omissão de boro.

Quando os sintomas de deficiência tornaram-se evidentes, procedia-se a descrição, sendo as cores fixadas com a ajuda do atlas de cores de VILALOBOS E VILALOBOS (1947). Por ocasião da coleta as plantas eram medidas em altura $(\mathrm{cm})$ a partir do colo até o ápice. Em seguida divididas em caules, folhas inferiores e superiores, flores e vagens, lavadas convenientemente com água desmineralizada e colocada a secar em estufa de circulação contínua de ar a $80^{\circ} \mathrm{C}$. O esquema experimental foi ao acaso. $\mathrm{O}$ material seco dos diversos órgãos foram moidos em moinho Wiley de peneira n. ${ }^{\circ} 20$, sendo posteriormente analisados quimicamente.

* Otto Baumgart Indústria e Comércio, São Paulo. 
TABELA 1 - Quantidade em mililitro das soluções estoque por litro de solução nutritiva nos diversos tratamentos. SARRUGE (1970)**

(1) $\mathrm{H}_{3} \mathrm{BO}_{3}-2,86 \mathrm{~g} ; \mathrm{MnCl}_{2} \cdot 4 \mathrm{H}_{2} \mathrm{O}-1,81 \mathrm{~g} ; \mathrm{ZnSO}_{4} \cdot 7 \mathrm{H}_{2} \mathrm{O}-0,22 \mathrm{~g}$; $\mathrm{CuSO}_{4} \cdot 5 \mathrm{H}_{2} \mathrm{O}-0,08 \mathrm{~g} ; \mathrm{H}_{2} \mathrm{Mo} \cdot \mathrm{O}_{4} \cdot \mathrm{H}_{2} \mathrm{O}-0,02 \mathrm{~g}$ por litro de solução estoque.

(2) Fe-EDTA (JACOBSON, 1951).

\begin{tabular}{|c|c|c|c|c|c|c|c|c|}
\hline \multirow{2}{*}{$\begin{array}{l}\text { Soluções } \\
\text { Estoque }\end{array}$} & \multicolumn{8}{|c|}{ TRATA $\mathrm{T}$ EN TOS } \\
\hline & $\begin{array}{c}\text { Comple- } \\
\text { to } \\
\mathrm{ml} / 1\end{array}$ & $\stackrel{\mathrm{I} / \mathrm{IU}}{-\mathrm{N}}$ & $\begin{array}{c}-\mathrm{P} \\
\mathrm{ml} / 1\end{array}$ & $\begin{array}{c}-\mathrm{K} \\
\mathrm{ml} / 1\end{array}$ & $\begin{array}{l}-\mathrm{Ca} \\
\mathrm{ml} / 1\end{array}$ & $\begin{array}{l}-\mathrm{Mg} \\
\mathrm{ml} / 1\end{array}$ & $\begin{array}{c}-\mathrm{S} \\
\mathrm{ml} / 1\end{array}$ & $\begin{array}{l}-\mathrm{B} \\
\mathrm{ml} / 1\end{array}$ \\
\hline $\mathrm{KH}_{2} \mathrm{PO}_{4} \quad \mathrm{M}$ & 1 & 1 & - & - & 1 & 1 & 1 & 1 \\
\hline $\mathrm{KNO}_{3} \quad \mathrm{M}$ & 5 & - & 5 & - & 5 & 3 & 3 & 5 \\
\hline $\mathrm{Ca}\left(\mathrm{NO}_{3}\right)_{2} \quad \mathrm{M}$ & 5 & 一 & 5 & 5 & - & 5 & 4 & 5 \\
\hline $\mathrm{MgSO}_{4} \quad \mathrm{M}$ & 2 & 2 & 2 & 2 & 2 & - & - & 2 \\
\hline $\mathrm{KC1} \mathrm{M}$ & - & 5 & 1 & - & - & 2 & 2 & - \\
\hline $\mathrm{CaCl}_{2} \mathrm{M}$ & - & 5 & - & - & - & 2 & 2 & - \\
\hline $\mathrm{NH}_{4} \mathrm{H}_{2} \mathrm{PO}_{4} \quad \mathrm{M}$ & - & - & - & 1 & - & - & - & - \\
\hline $\mathrm{NH}_{4} \mathrm{NO}_{3} \quad \mathrm{M}$ & - & 一 & - & 2 & 5 & - & - & - \\
\hline$\left(\mathrm{NH}_{4}\right)_{2} \mathrm{SO}_{4} \quad \mathrm{M}$ & - & - & - & - & - & 2 & - & - \\
\hline $\mathrm{Mg}\left(\mathrm{NO}_{3}\right)_{2} \quad \mathrm{M}$ & - & - & - & - & - & - & 2 & - \\
\hline $\begin{array}{l}\text { Micronu- } \\
\text { trientes (1) }\end{array}$ & 1 & 1 & 1 & 1 & 1 & 1 & 1 & - \\
\hline Fe-EDTA (2) & 1 & 1 & 1 & 1 & 1 & 1 & 1 & 1 \\
\hline $\begin{array}{l}\text { Micronu- } \\
\text { trientes-B }\end{array}$ & - & - & - & - & - & - & - & 1 \\
\hline
\end{tabular}

** Comunicação particular - Departamento de Química - E.S.A. "Luiz de Queiroz". 


\begin{tabular}{|c|c|c|c|c|}
\hline \multicolumn{3}{|c|}{ Tratamentos } & Solução Nutritiva & $\begin{array}{l}\text { Dias após a } \\
\text { germinação }\end{array}$ \\
\hline Completo & & & Macro + micronutrientes & 6 \\
\hline Omissão & de & $\mathbf{N}$ & Macro-N+micronutrientes & 24 \\
\hline$"$ & $"$ & $\mathbf{P}$ & Macro-P+micronutrientes & 24 \\
\hline$"$ & $"$ & $\mathrm{~K}$ & Macro-K+micronutrientes & 24 \\
\hline$"$ & $"$ & $\mathrm{Ca}$ & Macro-Ca+micronutrientes & 24 \\
\hline$”$ & $"$ & $\mathrm{Mg}$ & Macro-Mg+micronutrientes & 24 \\
\hline$"$ & $"$ & S & Macro-S + micronutrientes & 21 \\
\hline$"$ & $"$ & B & Macro-B + micronutrientes & 20 \\
\hline
\end{tabular}

O nitrogênio foi determinado pelo método Kjeldahl semi micro descrito por MALAVOLTA (1957).

No extrato nítrico-perclórico foram seguidas as recomendações de LOTT et alii (1956) na dosagem do fósforo; potássio por fotometria de chama, método de SARRUGE, (1971); enxofre pelo método do sulfato de bário de CHAPMAN E PRATT (1961). O boro foi determinado pelo método de JOHNSON e ULRICH (1959).

Cálcio e magnésio foram determinados no extrato nítrico-perclórico por espectrofotometria de absorção atômica, PERKIN-ELMER (1966).

\section{RESULTADOS E DISCUSSÃO}

\section{Sintomas e deficiência}

\subsection{Nitrogênio}

As plantas cultivadas em solução nutritiva com omissão de nitrogênio, eram raquíticas e pouco desenvolvidas. Os órgãos das plantas deficientes eram reduzidos a metade dos das sadías.

Após 11 dias de uso da solução nutritiva em que se omitiu o nutriente, observou-se um amarelecimento e secamento das folhas mais velhas. Os folíolos e estípulas inferiores apresentaram coloração amarelada (LLY 11-7. ${ }^{\circ}$ ), posteriormente secaram e cairam. Os 
correspondentes as plantas sadías eram de uma coloração verde vivo (LGL 6-9.9).

Esta clorose progrediu com o decorrer da deficiência, até atingir as folhas medianas e superiores.

Os folíolos e estípulas medianos apresentaram-se amarelados (L $11-10 .^{\circ}$ ), enquanto as plantas sadias apresentaram coloração verde intensa (GGL 7-6. ${ }^{\circ}$ ).

Folíolos e estípulas superiores das plantas deficientes apresentaram-se menos amarelados (LLG $10-100^{\circ}$ ) que os inferiores e medianos, porém em nítido contraste com os correspondentes das plantas sadías de coloração verde intensa (GGL 7-5. ${ }^{\circ}$ ).

Houve floração intensa das plantas deficientes, superior a observada nas plantas sadías.

A sintomatologia descrita aos 32 dias de uso da solução nutritiva deficiente concorda com a observada por Laurie e Wagner, (1940), citados por MALAVOLTA (1967).

Sendo a ervilha uma leguminosa, ela fixa o nitrogênio atmosférico através da simbiose das bactérias com as suas raízes, condições de solo tais como: má drenagem, ausência ou pequeno número de Rhizobium leguminosarum, reduzido teor de nitrogênio orgânico e inorgânico, reduzido teor de fósforo e potássio solúveis, presença de ferro e alumínio solúveis e indispobilidade do molibdênio devido ao baixo índice de $\mathrm{pH}$, limitam esta fixação segundo ALEXANDER (1961).

\subsection{Fósforo}

Plantas cultivadas em solução nutritiva com omissão de fósforo, apresentaram-se pouco desenvolvidas e tombadas. Os órgãos aéreos das plantas eram reduzidos e menores do que os das plantas sadías.

Após 26 dias de uso da solução nutritiva deficiente, iniciou-se o murchamento dos bordos das folhas inferiores. Os folíolos e estípulas, de coloração verde azulada (GGL 6-6. ${ }^{\circ}$ ), secaram e cairam com o progredir da carência. Os correspondentes das plantas sadías eram de coloração verde vivo (LG 5-7..$^{\circ}$ ).

Folíolos e estípulas medianos apresentaram também a coloração verde azulada (GGL $6-5 .^{\circ}$ ), ao passo que os correspondentes das plantas sadías eram de coloração verde vivo (LG 5-10.0).

A sintomatologia descrita aos 37 dias de uso da solução nutritiva deficiente, concorda a observada por WALLACE (1944). 


\subsection{Potássio}

Plantas vegetando em solução nutritiva na qual o potássio foi omitido, eram pequenas. Os órgãos foliares eram menores e os caules quebradiços.

Após 22 dias de uso da solução nutritiva deficiente, observou-se o amarelecimento das margens das folhas e estípulas mais velhas que secaram com o progredir da carência.

Os folíolos e estípulas medianos, com os bordos crestados, murchos e o interior do limbo de coloração amarelada (L 8-7. ${ }^{\circ}$ ). Os correspondentesd as plantas sadías eram de coloração verde escuro (LLG 5-5. ${ }^{\circ}$ ).

Observou-se que os folíolos e estípulas superiores das plantas deficientes, apresentaram início de crestamento dos bordos e amarelecimento do limbo (LLB 6-7. ${ }^{\circ}$ ). Os correspondentes das plantas sadías eram de coloração verde vivo (LLG 5-5.').

As plantas deficientes apresentaram flores em menor número que as sadías, como também vagens mal formadas e em menor número por planta.

O quadro sintomatológico observado aos 51 dias de uso da solução nutritiva deficiente concorda com o descrito por WOODMAN (1944).

\subsection{Cálcio}

As plantas cultivadas em solução nutritiva com omissão deste nutriente eram menos desenvolvidas que as sadías.

Após 24 dias de uso da solução nutritiva deficiente, as folhas mais velhas tornarams-e amareladas. Os folíolos murcharam com o progredir da carência e apresentaram os bordos voltados para a página inferior.

Folíolos e estípulas medianos com coloração internerval amarelada ( $\left.\mathrm{L} 9-11 .^{\circ}\right)$. O amarelecimento progrediu da ponta para a base do órgão foliar. Os correspondentes das plantas sadías permaneceram verdes ( $L L G 5-5 .^{\circ}$ ).

Flores e vagens eram em número reduzido quando comparadas com as plantas sadías.

O quadro sintomatológico descrito aos 51 dias de uso da solução nutritiva, concorda com o observado por DAY (1929). 


\subsection{Magnésio}

Plantas cultivadas em solução nutritiva com omissão de magnésio, tiveram desenvolvimento normal, devido talvez a grande quantidade do nutriente na semente e o absorvido nos primeiros dias de uso da solução nutritiva. Diferiram das sadías, no entanto, pela queda das folhas que foi mais evidente nas plantas deficientes.

Folíolos e estípulas inferiores murchos.

Os folíolos e estípulas medianos eram de uma coloração verde descorado ( $\mathrm{L} 7-100^{\circ}$ ), ao passo que as sadías eram de coloração verde vivo ( $L L G 4-5 .^{\circ}$ ).

Os órgãos foliares superiores das plantas deficientes pouco diferiram quanto a coloração das plantas sadías. Apresentaram tonalidade verde vivo (LLG 5-7..$^{\circ}$ ) para as plantas sadías. Flores e vagens abundantes.

A sintomatologia descrita aos 72 dias de uso da solução nutritiva deficiente em magnésio, discorda totalmente com a observada por Carolus e Brown (1935), citados por MALAVOLTA (1967).

Ciferri (sem data), citado por MALAVOLTA (1970), observou fato semelhante com o feijoeiro. A planta completou o ciclo vegetativo sem demonstrar falta de magnésio. $O$ autor afirmou que a quantidade de magnésio contida na semente foi suficiente para atender a necessidade da planta.

\subsection{Enxofre}

As plantas cultivadas em solução nutritiva com omissão de enxofre, tiveram desenvolvimento semelhante às sadías.

Folíolos e estípulas inferiores murchos. Os medianos amarelados (L 5-12..$^{\circ}$ ), ao passo que os das plantas sadías apresentaram coloracão verde vivo ( $L L G 4-5 . .^{\circ}$ ).

Os órgãos foliares superiores das plantas deficientes eram amarelados ( $\mathrm{L}$ 5-12..$^{\circ}$ ), e os correspondentes das folhas normais eram de coloração verde vivo (LLG 5-11. ${ }^{\circ}$ ). Flores e vagens abundantes.

Este quadro sintomatológico foi observado aos 72 dias após o uso da solução nutritiva deficiente.

HAAG et alii., (1968), também não obteve sintomas de deficiência de enxofre em cebola. Atribuiram ao sulfato ferroso, necessário para a preparação do Fe-EDTA, como fonte de enxofre suficiente para o desenvolvimento da planta. 


\subsection{Boro}

Plantas cultivadas em solução nutritiva com omissão de boro, eram menos desenvolvidas que as sadías. Apresentaram morte da gema apical e caules e folhas quebradiças.

Após 21 dias de uso da solução nutritiva deficiente, as folhas mais novas apresentaram escurecimento e murchamento dos ápices. Com o progredir da carência, observou-se que os folíolos e estípulas ficaram deformados devido ao secamento dos bordos apicais e a saliência das nervuras. A coloração destes órgãos era verde escuro (GGL 6-6..$^{\circ}$, ao passo que os sadíos tinham coloração verde mais clara (LG 5-10. ${ }^{\circ}$ ).

Os folíolos e estípulas medianos eram coriáceos, com os bordos queimados e de coloração verde escura (GGL 4-6. ${ }^{\circ}$ ), e os correspondentes sadíos também eram verde, porém mais claros (LG 5-9. ${ }^{\circ}$ ).

Folíolos e estípulas inferiores de coloração verde escura (GGL 5-9..$^{\circ}$ e posteriormente amareleceram e caíram. Os folíolos e estípulas sadios eram também verdes, porém mais claros (LG 5-7. ${ }^{\circ}$ ). Ausência total de flores.

A sintomatologia descrita aos 47 dias após o uso da solução nutritiva deficiente em boro, concorda com as observadas por Peper (1935), citado por MALAVOLTA (1967) e WOODBRIDGE (1969).

\section{Desenvolvimento das plantas}

O desenvolvimento das plantas dos tratamentos completos e deficientes foi avaliado através da altura $(\mathrm{cm})$ das plantas verdes e o peso da matéria seca ( $\mathrm{g}$ ) e os dados acham-se na Tabela 2.

Observou-se aos 57 dias após a germinação, que o tratamento que recebeu todos os nutrientes na solução nutritiva, apresentou o peso da matéria seca das raízes, cerca de cinco vêzes ao observado para o tratamento com omissão de nitrogênio. Tal redução no peso seco também foi observado, para os tratamentos que foram omitidos o fósforo e o boro. Por outro lado, as omissões de potássio, cálcio, magnésio e enxofre apresentaram pesos da matéria seca superiores aos tratamentos completos.

McMURTREY (1933), trabalhando com algodoeiro, ARZOLLA (1961) com abacaxizeiro, HAAG (1965) com cana-de-açúcar e COBRA NETO (1967) com feijoeiro, observaram que o peso da matéria seca das raízes das plantas cultivadas em solução nutritiva deficiente em enxofre, apresentaram pesos semelhontes às plantas sadías. 


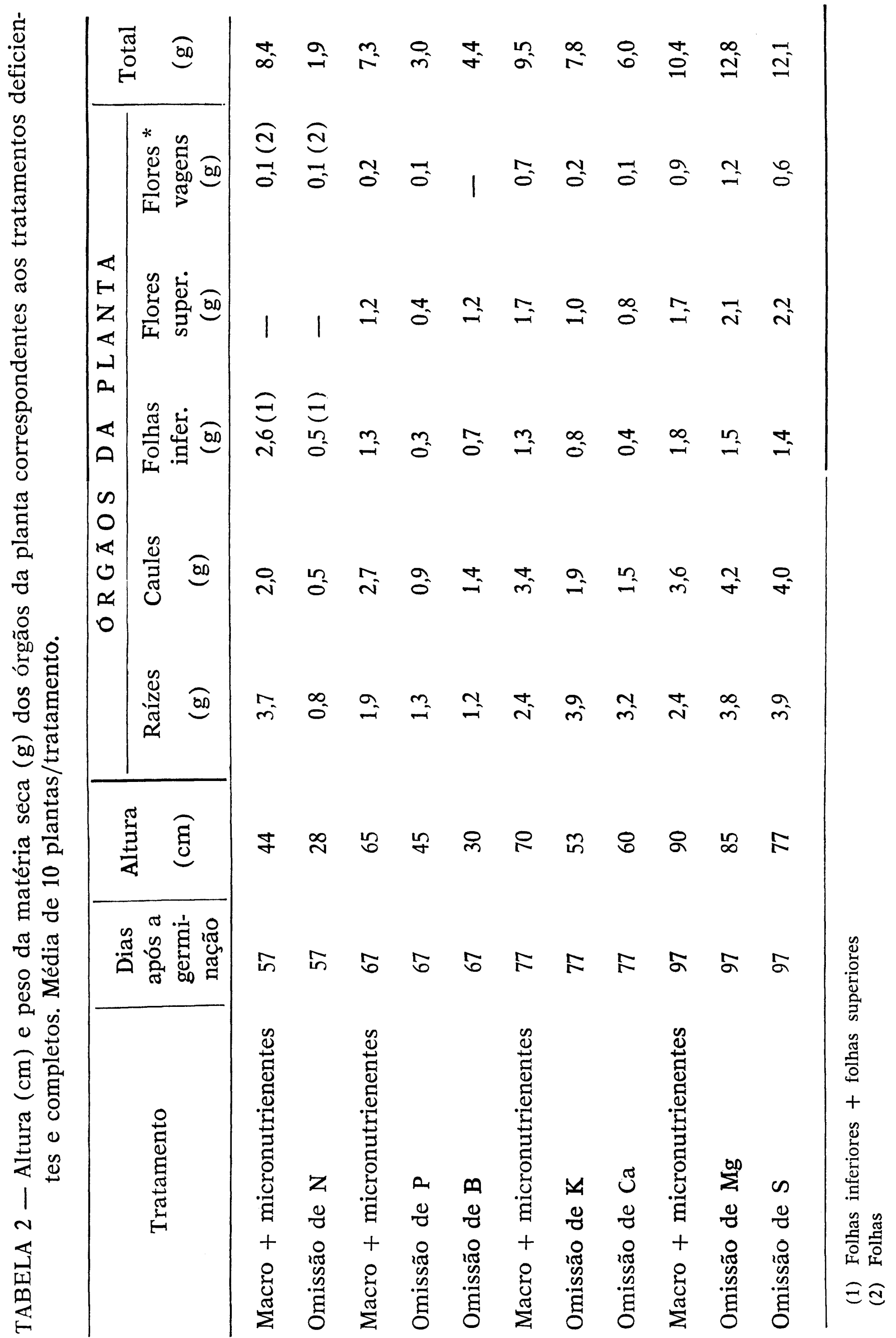


Também para os órgãos vegetativos, o nitrogênio apresentou-se como o nutriente mais limitante da produção da matéria seca. Os nutrientes fósforo, cálcio, potássio e boro seguiram-lhe em importância na limitação. As plantas cultivadas com omissão de magnésio e enxofre apresentaram peso da matéria seca superior, às sadías.

O peso da matéria seca das flores para os tratamentos completo e deficiente em nitrogênio, foram iguais, devido a intensidade de floração do segundo. As produções de vagens de todos os tratamentos com omissões, com excessão da do magnésio, foram inferiores aos completos correspondentes. $\mathrm{O}$ boro foi o nutriente que mais afetou a produção.

Atribuindo-se aos tratamentos completos o valor 100 e exprimindo-se os deficientes em percentagens destes, observou-se que os tratamento reduziram a matéria seca na seguinte ordem decrescente: nitrogênio $77 \%$, fósforo $59 \%$, boro $40 \%$, cálcio $37 \%$, potássio $18 \%$.

O fato de plantas cultivadas em solução nutritiva deficiente em magnésio e enxofre, apresentaram peso de matéria seca maior que as completas, foi observado também por HAAG (1965), em estudos com cana-de-açúcar e posteriormente HAAG et alii., (1968), em trabalhos com cebola. Nêste último, os autores observaram que a ausência do nitrogênio reduziu em $74 \%$ e a do cálcio em $67 \%$ o peso da matéria seca em relação às sadías. Valor para o nitrogênio, apesar de a cebola ser outra espécie vegetal, bastante próximo do encontrado para ervilha.

\section{Teores dos nutrientes}

Os teores dos macronutrientes e boro nos órgãos das plantas para os diversos tratamentos encontram-se na Tabela 3.

O teor nitrogênio observado nas folhas das plantas sadías aos 50 dias, foi superior a 3,5\%, citado por LAVALLEYE e STEPPE (1966) como adequado. Por outro lado, o teor $3,0 \%$ para o potássio, considerado pelos autores como adequado, foi superior ao observado.

$\mathrm{O}$ teor de fósforo encontrado nas folhas superiores das plantas deficientes neste tratamento, foi igual ao citado por KLACAN e BERGER (1963) e LAVALLEY e STEPPE (1966), como teor adequado $(0,2 \%)$ e para as plantas sadías, o teor encontrado foi o dobro daquele indicado pelos autores $(0,25 \%)$.

O teor de cálcio encontrado, concorda com $1,0 \%$, valor considerado como adequado na ocasião do florescimento por MACLEAN e BYERS (1968), no entanto o valor correspondente ao magnésio, $0,3 \%$, foi inferior ao observado neste estádio. 


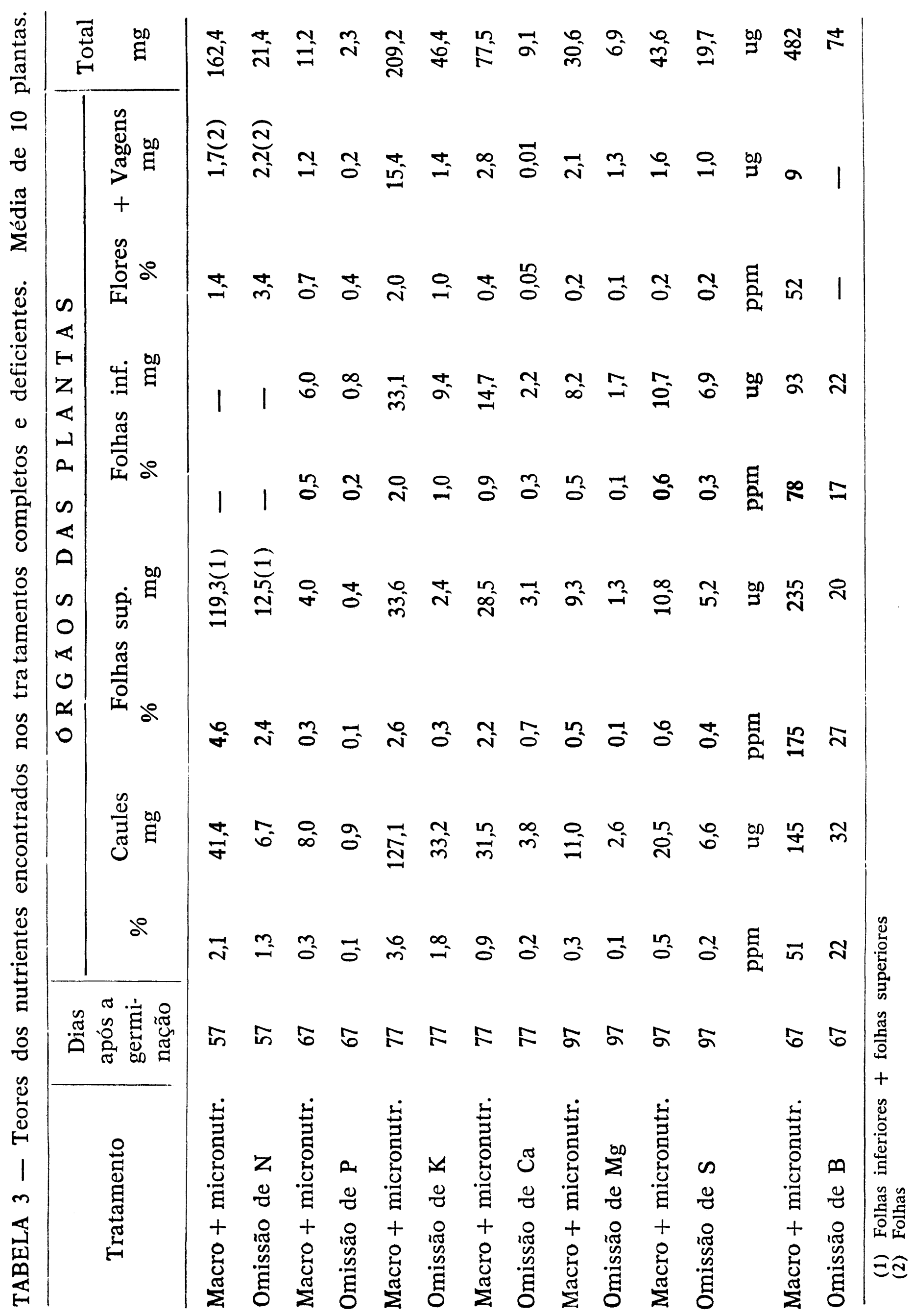


E para o boro, os autores afirmam que mesmo sem surgirem sintomas visuais de deficiências, o teor de $18 \mathrm{ppm}$ observado, estava possivelmente na faixa de fome oculta. $O$ valor encontrado neste trabalho concorda com o observado pelos autores.

Apesar de não se ter constatado a deficiência de magnésio e enxofre nas plantas cultivadas com omissão dos nutrientes, observou-se que os teores dos citados nutrientes nos órgãos vegetativos das plantas deficientes eram reduzidos quando comparados com as sadías. Nos órgãos reprodutivos, no entanto, esta diferença era menor, devido talvez, a mobilização deste dos órgos vegetativos.

A distribuição dos nutrientes nos órgãos das plantas deficientes e sadías não foi idêntica. Enquanto nas plantas sadías o nitrogênio concentrou-se nas folhas, nas plantas deficientes, no entanto, as flores é que apresentaram o teor mais elevado do nutriente, devido talvez a mobilização deste dos outros órgãos da planta. Tal fato também ocorreu com o fósforo, no entanto, foi na porção superior das folhas das plantas sadías que verificou-se a maior concentração do nutriente. O mais alto teor de potássio, tanto nas plantas sadias quanto nas deficientes, foi verificado nos caules. As folhas inferiores das plantas sadías e deficientes, apresentaram teor mais elevado de cálcio. As plantas sadías apresentaram teores mais elevados de magnésio e enxofre nas folhas, porém as deficientes em magnésio apresentaram uma distribuição igual do nutriente nos órgãos da planta; ao passo que nas deficientes em enxofre, o nutriente concentrou-se nas folhas inferiores. Os teores mais elevados em ppm de boro nas plantas sadías e deficientes, encontrou-se nas folhas infreiores.

Os teores totais em miligrama dos nutrientes nitrogênio, fósforo, potássio, cálcio e boro encontrados nas plantas sadías foram $80 \%$ maiores que os das plantas deficientes; nas plantas deficientes em magnésio e enxofre, a diferença foi de cerca de aproximadamente $75 \%$ e $55 \%$, respectivamente.

Atribuindo-se o valor 100 aos teores em miligrama dos nutrientes nas plantas completas, e exprimindo-se os teores dêstes nutrientes nas plantas deficientes em percentagens, observa-se os seguintes valores: para nitrogênio e cálcio houve uma redução de $88 \%$, para o magnésio $87 \%$, para o boro $85 \%$, para o fósforo $80 \%$, para o potássio $78 \%$ e para o enxofre $55 \%$. Observa-se que o enxofre foi o nutriente que mais acumulou-se nas plantas deficientes, reforçando portanto, os fatores citados anteriormente como responsável pela inexistência do aparecimento dos sintomas visuais de carência.

\section{CONCLUSÕES}

1 - As omissões dos macronutrientes com excessão do magnésio 
e do enxofre, apresentaram sintomas visuais de deficiência características.

2 - A produção de matéria seca foi afetada em todos os tratamentos com omissão de nutrientes, com excessão daqueles nos quais foram omitidos o magnésio e/ou enxofre.

3 - Os teores dos nutrientes expressos em porcentagem e/ou partes por milhão em fôlhas apresentando ou não sintomas de carências foram:

\begin{tabular}{lcccc}
\hline \multirow{2}{*}{ Nutriente } & \multicolumn{2}{c}{ Folhas Inferiores } & \multicolumn{2}{c}{ Folhas Superiores } \\
\cline { 2 - 5 } & $\mathrm{c} /$ sintomas & $\mathrm{s} /$ sintomas & $\mathrm{c} /$ sintomas & $\mathrm{s} /$ sintomas \\
\hline Nitrogênio & $2,4 \%(1)$ & $3,6 \%(1)$ & - & - \\
Fósforo & $0,1 \%$ & $0,3 \%$ & $0,2 \%$ & $0,5 \%$ \\
Potássio & $0,3 \%$ & $2,6 \%$ & $1,0 \%$ & $2,0 \%$ \\
Cálcio & $0,7 \%$ & $2,2 \%$ & $0,3 \%$ & $1,0 \%$ \\
Magnésio & $0,1 \%$ & $0,5 \%$ & $0,1 \%$ & $0,5 \%$ \\
Enxofre & $0,3 \%$ & $0,6 \%$ & $0,3 \%$ & $0,6 \%$ \\
Boro & $27 \mathrm{ppm}$ & $175 \mathrm{ppm}$ & $17 \mathrm{ppm}$ & $78 \mathrm{ppm}$ \\
\hline
\end{tabular}

(1) Folhas inferiores + folhas superiores

\section{SUMMARY}

- Mineral NUTRITION OF PEAS (Pisum sativum L.3, VARIETIF.S ASGROW 40 AND OKAW.

Deficiencies of the macronutrients and boron.

The presente work was carried out in order to study:

a - The effect of the omission and presence of the macronutrients and boron on the growth of the plants - variety Asgrow 40;

b - deficiency symptoms of macronutrients and boron in the same variety;

c - the effects of the deficiencies of each macronutrient and boron on the dry matter production and on the chemical composition of the plant-variety Asgrow 40. 


\section{I - Deficiencies of the macronutrients}

Young peas plants (Pisum sativum, L.), variety Asgrow 40 were grown in pots containing pure quartz. Several times a day they were irrigated by percolation with nutrient solution.

The treatments were: complete solution and deficient solution, in which each one of the macronutrient was omitted as well boron. Soon as the malnutrition symptoms apperared, the plants were harvested and divided into: roots, stalks, inferior and superior leaves, flowers, husk containing the seeds. The dry matter was analysed chemically.

\section{Conclusions :}

1 - Symptoms of malnutrition were observed for $\mathrm{N}, \mathrm{P}, \mathrm{K}, \mathrm{Ca}$ and $\mathrm{B}$;

2 - The omission of the macronutrients and boron affected the dry matter production, excepted for magnesium and or sulphur;

3 - The nutrient content in the dry matter, expressed in porcentages (\%) and or parts per million ( $\mathrm{ppm}$ ) in deficient leaves and healthy leaves were:

\begin{tabular}{ccccc}
\hline \multirow{2}{*}{ Nutrient } & \multicolumn{2}{c}{ Inferior leaves } & \multicolumn{2}{c}{ Superiores leaves } \\
\cline { 2 - 5 } & deficient & healthy & deficient & healthy \\
\hline $\mathrm{N}$ & $2.4 \%(1)$ & $4.6 \%(1)$ & - & - \\
$\mathrm{P}$ & 0.1 & 0.3 & $0.2 \%$ & $0.5 \%$ \\
$\mathrm{~K}$ & 0.3 & 2.6 & 1.0 & 2.0 \\
$\mathrm{Ca}$ & 0.7 & 2.2 & 0.3 & 1.0 \\
$\mathrm{Mg}$ & 0.1 & 0.5 & 0.1 & 0.5 \\
$\mathrm{~S}$ & 0.3 & 0.6 & 0.3 & 0.6 \\
$\mathrm{~B}$ & $27 \mathrm{ppm}$ & $175 \mathrm{ppm}$ & $17 \mathrm{ppm}$ & $78 \mathrm{ppm}$ \\
\hline
\end{tabular}

(1) Inferior and superior leaves

\section{6 - LITERATURA CITADA}

ALEXANDER, M. 1961 - Introduction to soil microbiology New York, John Wiley e Sons. Inc, U.S.A. 
ARZOLLA, S. 1961 - Estudos sobre a nutrição mineral do abacaxizeiro (Ananas sativas, Schult). "Tese". E.S.A. "Luiz de Queiróz", Piracicaca, São Paulo, (mimeo.).

BERNARDI, J. B. 1961 - Instruções práticas: Cultura da ervilha. O agronomico. I.A.C., Campinas, São Paulo, 13(9-10):11-14.

CHAPMAN, H. D. e PRATT, P. F. 1961 - Methods of analysis for soils plant and waters: Total sulfur in plants. California.

COBRA NETO, A. 1967 - Absorção e deficiências dos macronutrientes pelo feijoeiro (Phaseolus vulgaris, L., var. roxinho). "Tese". E. S. A. "Luiz de Queiróz", Piracicaba, São Paulo. (mimeo.).

DAY, D. 1929 - Some effects of calcium deficiency on Pisumsativum. Plant Physiol. Lancaster, PA, 4:493-506.

HAAG, H. P. 1965 — Estudos de nutrição mineral na cana-de-açucar (Saccharum officinarum, L.) variedade CB 41-76 cultivada em solução nutritiva. “Tese". E.S.A. "Luiz de Queiróz", Piracicaba, São Paulo (mimeo.).

HAAG, H. P. e HOMA, P. 1968 - Nutrição mineral de hortaliças: Deficiência de macronutrientes em beringela. Anais da E.S.A. "Luiz de Queiróz". Piracicaba, São Paulo, 26:149-159.

HOWARD, F. D., McGILLIVRAY, J. H. e YAMAGUCHI, M. 1962 - Nutrient composition of fresh California-grow vegetables. California, U. S. A. (788): 43 .

JACOBSON, L. 1951 - Maintenance of iron supply in nutrient solutions by a single additon of jerric potassium ethylenedramine tetraacetate. Plant. Physiol. 26:411-413.

JOHNSON, C. M., A. ULRICH 1959 - II Analytical methods for use in plant analysis. Calif. Agr. Sta Exp. Bull. 766. Berkelay, California, USA.

KLACAN, G. R. e BERGER, K. C. 1963 - Effect of nitrogen and magnesium nutrition on pod and seed development in canning peas. Agron. J. Madison, USA, 55(2):228-231.

LAVALLEYE, M. e STEPPE, H. H. 1966 - Effects of potash on pea growth and quality. Simposium Potassium. Berna, Switzerland, 8:325-248.

LOTT, W. L., NERY, J. P., GALLO, J. R. e MEDSCALF, J. C. 1956 - A técnica da análise foliar aplicada ao cafeeiro. Boletim. I. A. C., Campinas, São Paulo, 79.

MACLEAN, K. S. e BYERS, D. L. 1968 - Nutrient content of fieldgrown peas. Can. J. Plant Sci. New Scotia, Canadá, 48:155-156.

MALAVOLTA, E. 1957 - Práticas de química orgânica e biológica. Centro Acadêmico "Luiz de Queiróz", Piracicaba, São Paulo.

MALAVOLTA, E. 1967 - Manual de química agrícola: Sintomas de deficiência. 2 ed. São Paulo, Editora Agronômica Ceres.

MALAVOLTA, E. 1970 - Nutrição mineral de plantas. Curso Pós Graduado de Solos e Nutrição de Plantas, Piracicaba, São Paulo, 218 (mimeo.).

McMURTREY, J. E. 1933 - Distintive effects of the deficiency of certain essential elements on the growth of cotton plants in solution cultures. Techn. Bull. Washington, D.C.

PERKIN-ELMER., 1966 - Analytical methods for atomico absorption specto photometry. Perkin-Elmer Corp. Connecticut, U.S.A. 
ROCHA, F. F., 1960 - Cultura da ervilha. Hortaliças. Viçosa, Minas Gerais, (7):1-19.

SARRUGE, J. R., 1971 - Coleta e preparo das amostras vegetais para análise. Curso Pós-Graduado de Solos e Nutrição de Plantas, Piracicaba, S. Paulo, (mimeo.).

VIlALOBOS, C. D. e VIlalobOS, J. 1947 - Atlas de los colores. Buenos Aires, Argentina, El ateneo Editorial.

WALLACE, T., 1944 - The diagnosis of mineral deficiencies in plants by visual symptons. London.

WOODBRIDGE, C. G., 1969 - Boron deficiency in pea Pisum sativum cv. "Alaska". J. Amer. Soc. hort. Sci. Michigan, U.S.A. 94(5):542-544. 
